\title{
The effect of dental gel formulation on human primary fibroblasts — an in vitro study
}

\author{
Barbara Sterczala $^{1}$, Julita Kulbacka², Jolanta Saczko², Marzena Dominiak ${ }^{1}$ \\ ${ }^{1}$ Department of Dental Surgery, Wroclaw Medical University, Wroclaw, Poland \\ ${ }^{2}$ Department of Molecular and Cellular Biology, Wroclaw Medical University, Wroclaw, Poland
}

\begin{abstract}
Introduction. In ordinary dental practice, the dentist often meets with patients suffering from ulcers, aphtha with edema, bleeding gums, bothersome burning, and dry mouth. These are prosthetic, orthodontic patients, after surgery, in various age ranges. Protefix ${ }^{\oplus}$ gel is a soothing and regenerating preparation aimed at patients with mucosal problems. The aim of our study was to evaluate the protective properties and the safety of Protefix ${ }^{\circledR}$ gel application after dental procedures in vitro.

Material and methods. Human gingival fibroblasts (HGFs) were isolated from normal gingival tissues, cultured to full monolayer and exposed to Protefix ${ }^{\circledast}$ gel in the concentration from 1 to $100 \%$. The viability of cells was examined by MTT assays. Cell migration as a response of treated cells was assessed. The expression of collagen III was estimated by immunocytochemistry after 20 minutes or 24 hours incubation with Protefix ${ }^{\circledR}$ gel.

Results. The obtained results indicated that the verified gel significantly stimulated fibroblasts' proliferation, and mitochondrial activity determined by MTT assay increased almost two-fold for lower gel concentrations. The immunohistochemical detection of collagen III revealed an increased expression after incubation with 5\% gel. Conclusions. The results proved that the gel is safe for cells derived from human gingiva and moreover has regenerative properties, which can be of great importance in the treatment of gingivitis after retraction and surgical procedures, or even ordinary daily injuries of oral cavity. (Folia Histochemica et Cytobiologica 2020, Vol. 58, No. 2, 156-161)
\end{abstract}

Key words: Protefix ${ }^{\circledast}$ gel; human gingival fibroblasts; cell proliferation; collagen III

\section{Introduction}

In everyday dental practice, the dentist often meets with patients suffering from ulcers, aphthae with edema, bleeding gums, bothersome burning, and dry mouth. These are prosthetic, orthodontic patients, after surgery, in various age ranges. The etiology of oral mucosal damage is variable. Protefix ${ }^{\circledR}$ gel is a gentle and redeveloping preparation, which can be effectively applied by patients with mucosal problems.

It is considered that orthodontic appliances and moveable prosthetic restorations can cause numerous mucosal injuries, chronically irritating sharp gingival

Correspondence address: Barbara Sterczala,

Department of Dental Surgery, Wroclaw Medical University,

Krakowska 26, 50-425 Wroclaw, Poland

tel.: +48 502932269

e-mail: barbara.sterczala@umed.wroc.pl edges of the gum-bone surface. Other problems occur when the denture is not properly adjusted and this leads to proliferative lesions in the form of fibromuscular hypertrophic changes of the oral mucosa. Then, the treatment consists of the surgical removal of pathological granulomatous hyperplasia $[1,2]$. Such procedures are often conducted in elderly patients, who very often suffer from other systemic diseases. Therefore, the healing process of extensive wounds of gingival tissues is sustained and painful. An unadjusted adaptation of prosthetic restorations to short-circuit conditions is the reason for residual debris and for reasons apart from mechanical irritation of the mucosa, bacteria and fungi develop.

As a result of chemical-toxic factors such as dental materials and solutions, for example mercury, nickel, and paraformaldehyde, allergic reactions may occur in the form of redness or burning. Among the systemic factors that can irritate the oral mucosa, we can dis- 


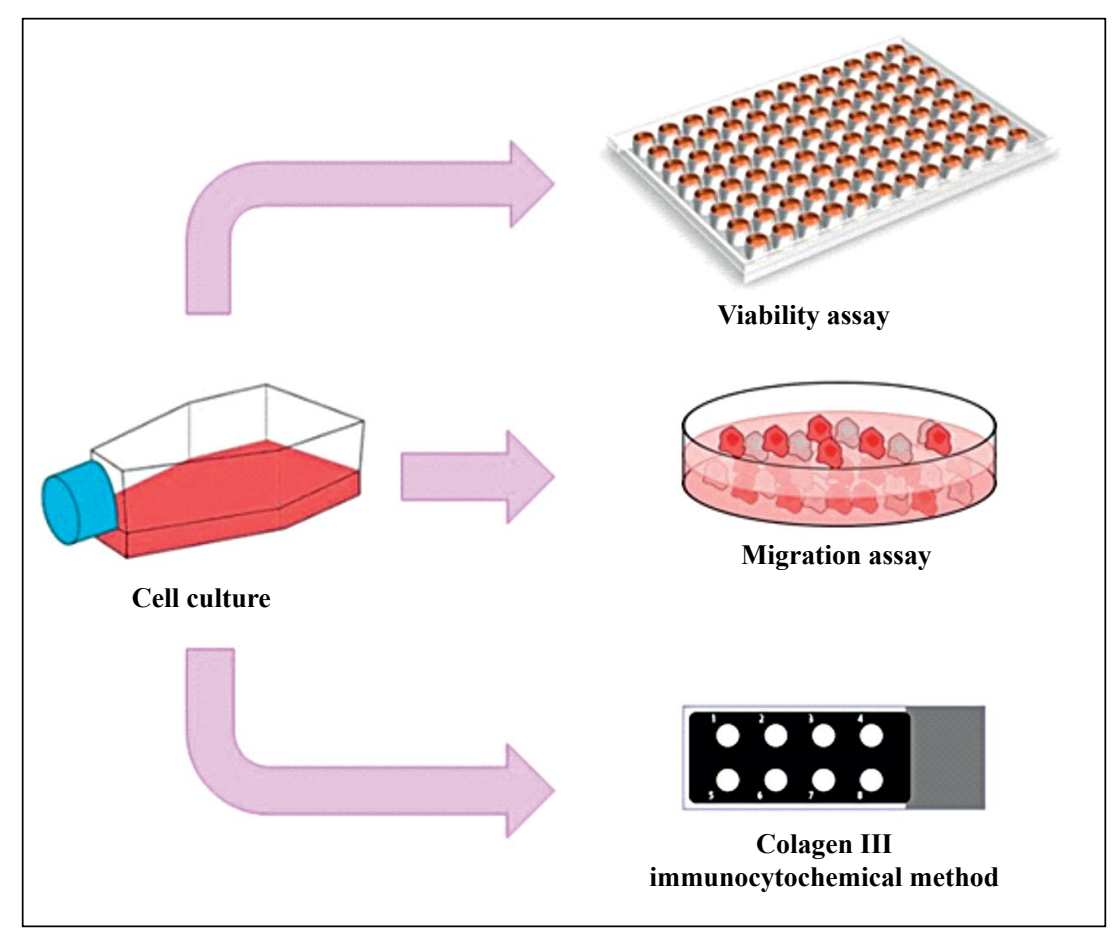

Figure 1. Schematic representation of Protefix ${ }^{\circledR}$ gel experimental verification by MTT, migration assay and immunocytochemistry.

tinguish: psychosomatic diseases like hypertension or diabetes, hormonal changes, deficiency diseases of the oral mucosa like anemia or Sjogren syndrome that can provoke symptoms such as dry mouth and burning mucous. Therefore, drug-induced gingival papillae are exposed to injuries even at brushing, and the resulting pain discourages patients from regular daily hygiene which further escalates the problem of inflammation [2-4].

Protefix $^{\circledR}$ gel, by dint of its gel form, is easy to apply and effects the extended penetration time of active substances into the tissue. The glyceroloxydtriester contained in the composition forms a lipid film on the gum with a protective and regenerating effect. Therefore, Protefix ${ }^{\circledR}$ gel is mainly targeted at patients suffering from abrasions or minor wounds of the oral mucosa. Additionally, the clove oil contained in Protefix ${ }^{\circledR}$ gel may minimize postoperative pain. In addition to its anesthetic properties, clove oil also exhibits antibacterial properties and eliminates bacteria including Escherichia coli, Mycobacterium phlei, Bacillus subtillis, and Streptoccocus ureus [5,6]. The oil also acts antiseptically, antivirally and against fungal infection. The clove oil speeds up circulation, which results in better wound healing [3, 7-9]. Untreated changes in the oral mucosa may initiate the formation of periodontal disease, bone loss, loss of teeth, or cancer. Besides, the discomfort of painful lesions on the oral mucosa impedes the proper functioning of patients in society.

The aim of our study was to evaluate the protective properties and the safety of Protefix ${ }^{\circledast}$ gel application in human gingival fibroblasts from primary culture after the simulation of dental procedures in vitro.

\section{Materials and methods}

Cell culturing. Human gingival fibroblasts (HGFs) were used for the experimental protocols. The HGFs were isolated from healthy gingival tissues according to a procedure described previously (Patent No: P 3812045) [10]. Cells were cultured in Dulbecco's Modified-Eagle Medium (DMEM, Sigma-Aldrich, Poznan, Poland) containing 10\% fetal bovine serum (Gibco-ThermoFisher, Warsaw, Poland) and enriched in 5\% antibiotic/antimycotic solution (Sigma-Aldrich). The cultured medium was changed twice a week. The cell culture and all procedures were performed under sterile conditions using laminar flow hood. Cells were kept in a humidified atmosphere at $37^{\circ} \mathrm{C}$ and $5 \% \mathrm{CO}_{2}$. For further experiments fibroblast cells (Fig. 1) were detached from the cell culture flask by trypsin ( $0.25 \%$ Trypsin-EDTA, Sigma-Aldrich) and resuspended in appropriate cell culture dishes.

Cell viability assay. HGFs were seeded into transparent 96-well plates. After 24 h, Protefix ${ }^{\circledast}$ gel (Quiesser Pharma 
Poland Sp z o.o., Warsaw, Poland) was added at various dilutions $(1,5,10,25,50,75$ and $100 \%)$ for $20 \mathrm{~min}$ or $24 \mathrm{~h}$ incubation. Gel dilutions (1-75\%) were prepared in cell culture medium and added in volume of $200 \mu \mathrm{l} /$ well to the 96-well plate. Control cells were incubated for the same time in the presence of the complete cell culture medium. All experiments were performed in triplicate. After the incubation, an MTT assay (Sigma-Aldrich) was performed to determine the cell viability. The method is based on the detection of activity of the mitochondrial enzyme succinate dehydrogenase. This converts the orange, water-soluble tetrazole salt (3-(4,5-dimethylthiazol-2-yl)-2,5-diphenyltetrazolium bromide) to formazan. This product has the form of dark purple, insoluble crystals. Due to their dissolution with isopropanol (they are not soluble in water), a colored solution is formed. The intensity of the colored reaction is verified spectrophotometrically at $570 \mathrm{~nm}$. The amount of the resulting colored product indicates the oxidative activity of the mitochondria in the cells, and thus the number of viable cells in the entire population (the more reduced the MTT, the greater the number of metabolically active cells). The measurements were performed on a Multiskan ${ }^{\mathrm{TM}}$ FC microplate photometer (Thermo Scientific, Alab, Warsaw, Poland).

Evaluation of cellular migration. The evaluation of cell migration was performed on Nunc $35 \mathrm{~mm}$ Petri dishes (Biokom, Janki, Poland). Protefix ${ }^{\circledR}$ gel drops (100\% concentration) were applied to sterile dishes. The plate was then covered with a fibroblast suspension at the density of $5 \times 10^{3}$ cells. All observations of cell migration in the presence of the gel were carried out after 24 and 48 hours using an Olympus CX41 (Olympus, Tokyo, Japan) inverted light microscope.

Immunocytochemical evaluation of collagen III. Human normal fibroblasts were placed onto 10-well microscopic slides (Menzel, Equimed, Wroclaw, Poland). After $24 \mathrm{~h}$ when the cells were attached to the surface, Protefix ${ }^{\circledR}$ gel dilutions were added to the cells. The expression of collagen III was estimated using immunocytochemistry after 20 minutes and 24 hours incubation with Protefix gel and fixed in $4 \%$ fresh paraformaldehyde (Roth, Karlsruhe, Germany). Cells were stained using rabbit polyclonal collagen III (cat. No.: sc-271249, Santa Cruz, CA, USA). Collagen type III and $I$ are the main ingredients of the interstitial matrix and play the main role in remodeling and reconstruction of the external matrix while type III collagen together with type I collagen are the main constituents of the interstitial matrix. Type III is especially responsible for wound healing [11]. The antibody was diluted with PBS buffer in the proportion 1:200. The detailed protocol was performed according to our previous study [12]. The quantification of the level of stained reaction in treated cells that revealed immunocytochemical reaction was estimated as a percentage values. The stained

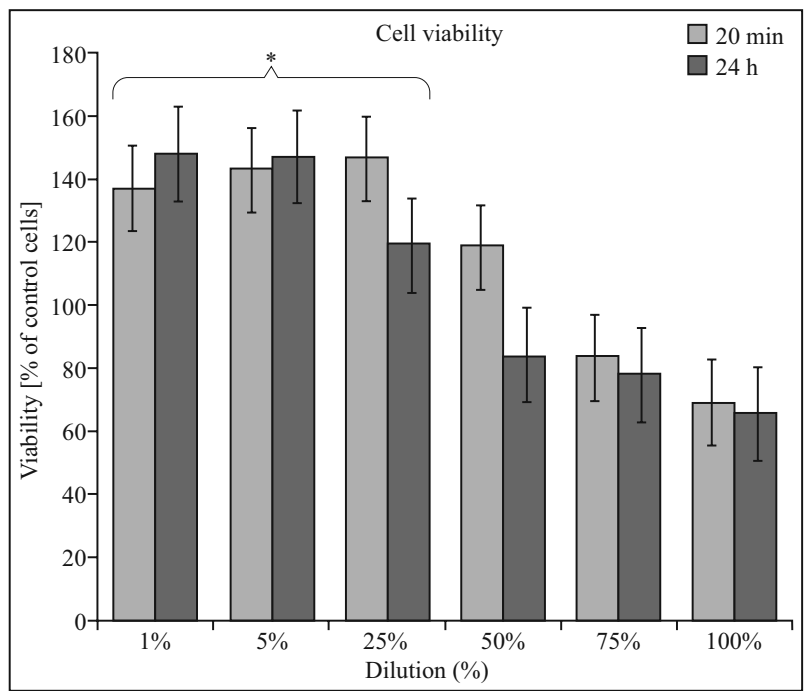

Figure 2. The impact of Protefix ${ }^{\circledR}$ gel in various dilutions on human gingival fibroblasts after exposure for $20 \mathrm{~min}$ and $24 \mathrm{~h}$ time. X-axis: dilution level of used gel, Y-axis cell viability expressed as a percentage of control cells. The results are presented as mean values of the percentage of the untreated control cells. Data represent mean values of a minimum of triplicate repetitions $* \mathrm{p} \leq 0.05$.

cells' counting was performed by two independent investigators. The intensity of immunoassayed reaction was evaluated as $(-)$ negative (no reaction), $(-/+)$ pattern reaction; $(+)$ weak, $(++)$ moderate, and $(+++)$ strong.

Statistical analysis. The statistical significance was calculated by two-way ANOVA test using the control group of the untreated fibroblasts incubated as a reference. Values were presented as a mean $\pm \mathrm{SD} ; \mathrm{n}=3$ and judged as a statistically significant for $\mathrm{p}<0.05$.

\section{Results}

\section{Cell viability by MTT assays}

The results of cell viability after exposition to gel in various concentrations are shown in Figure 2. We observed a tendency to a slight, statistically not significant decrease in cell viability after exposition to $100 \%$ and $75 \%$ gel concentration. The lower concentrations (1-25\%) of the examined gel showed significantly stimulating properties in terms of cell proliferation which increased by more than $50 \%$ in relation to untreated control cells (where the level of control cells was $100 \%$ ).

\section{Evaluation of cellular migration}

In another experiment, cell migration ability was tested in the presence of Protefix ${ }^{\circledR}$ gel (Fig. 3). These observations showed a fairly high cell affinity for the 

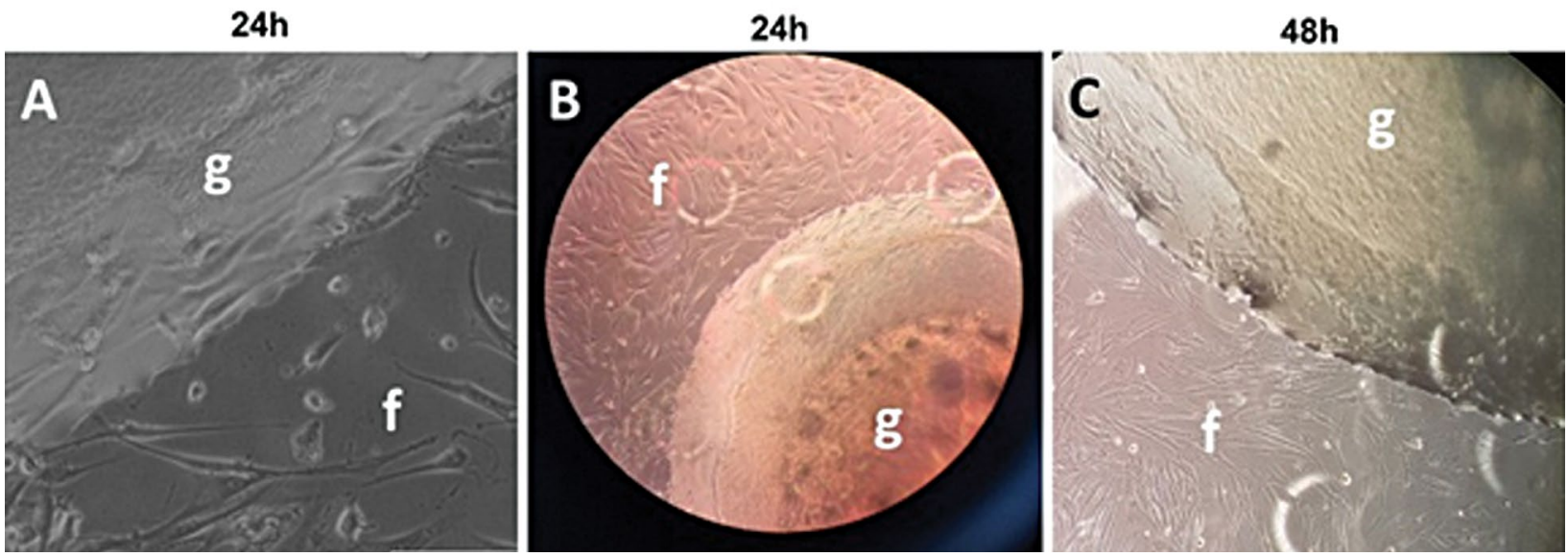

Figure 3. The effect of Protefix ${ }^{\circledR}$ gel in $100 \%$ concentration (placed on the culture plate) on human gingival fibroblasts migration ability after $24 \mathrm{~h}$ (A and B) and $48 \mathrm{~h}$ (C) time of exposure. Symbols: $\mathrm{g}$ - gel; $\mathrm{f}$ - fibroblasts.

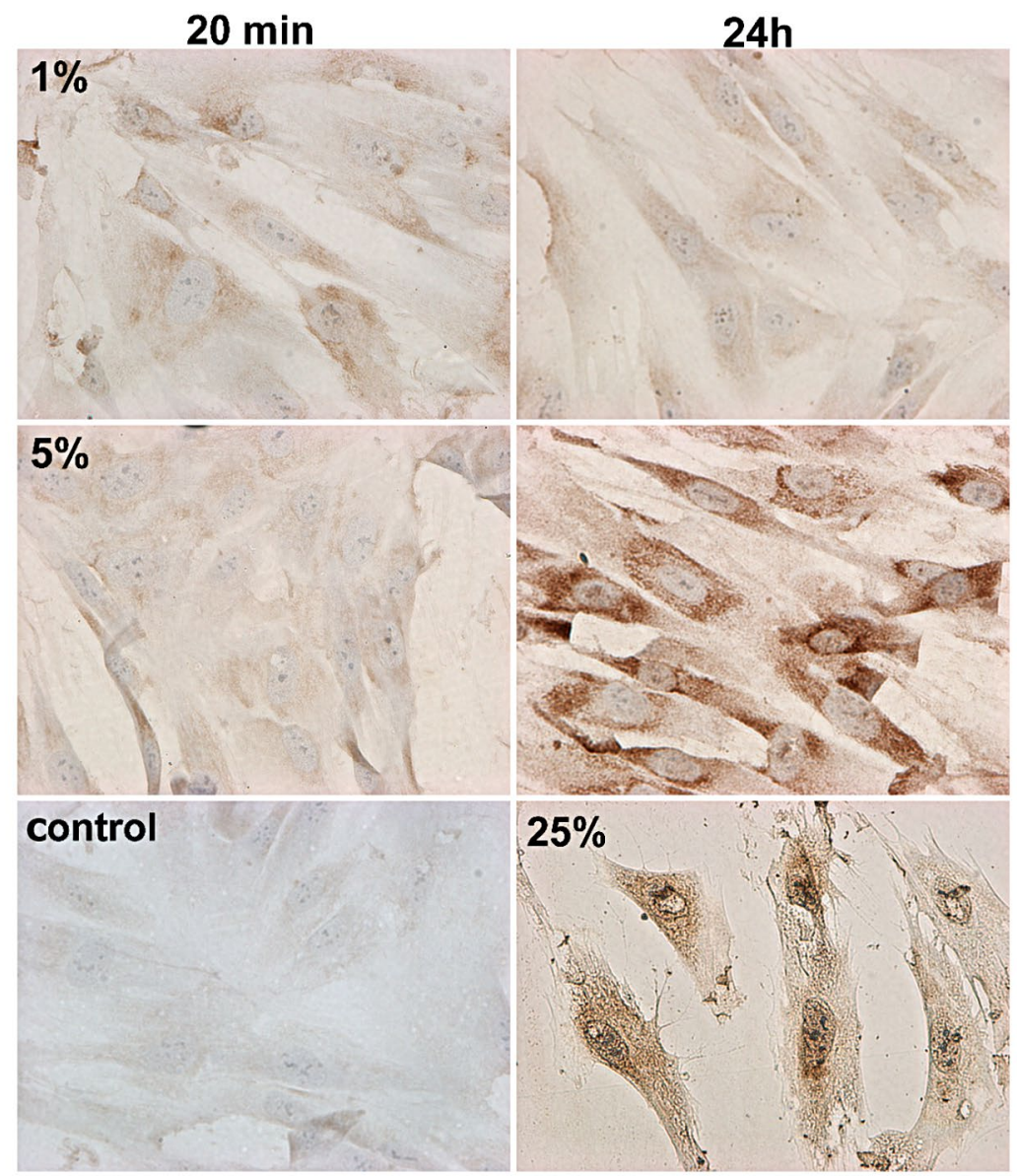

Figure 4. Immunohistochemical visualization of collagen III expression in human gingival fibroblasts after exposure to Protefix $^{\circledR}$ gel in concentrations of $1 \%, 5 \%$ and $25 \%$ for $20 \mathrm{~min}$ and $24 \mathrm{~h}$.

gel. Here we could observe that fibroblasts grew rapidly to form a full monolayer in the gel-coated area on the Petri dish. Even prolonged observations of up to 48 hours showed that the presence of the gel had a positive rather than inhibitory effect on cell growth.

\section{Estimation of Collagen III} by the immunocytochemical method

The results of the immunostained reaction are presented in Figure 4. In Table 1 is shown the quantification of the percentage values of the cells characterized 
Table 1. Semi-quantitative assessment of collagen III expression in human gingival fibroblasts after exposure to Protefix ${ }^{\circledR}$ gel in concentrations of $1 \%, 5 \%$ and $25 \%$ for $20 \mathrm{~min}$ and $24 \mathrm{~h}$. The results were classified as positive if staining was observed in more than $5 \%$ of cells. The intensity of immunohistochemical reaction was evaluated as $(-)$ negative (no reaction $) ;(-/+)$ pattern reaction; $(+)$ weak, $(++)$ moderate, and $(+++)$ strong

\begin{tabular}{|c|c|c|}
\hline Sample & $20 \mathrm{~min}$ & $24 \mathrm{~h}$ \\
\hline $1 \%$ gel & $\begin{array}{c}++ \\
100 \%\end{array}$ & $\begin{array}{c}++ \\
100 \%\end{array}$ \\
\hline $5 \%$ gel & $\begin{array}{c}++ \\
95 \%\end{array}$ & $\begin{array}{c}+++ \\
100\end{array}$ \\
\hline $25 \%$ gel & $\begin{array}{c}++/+++ \\
100 \%\end{array}$ & $\begin{array}{c}+++ \\
100\end{array}$ \\
\hline Untreated control & $\begin{array}{l}-/+ \\
90 \%\end{array}$ & $\begin{array}{l}-/+ \\
100 \%\end{array}$ \\
\hline
\end{tabular}

by stained reaction demonstrating collagen III. The obtained results revealed the trace expression of this protein in control cells. After the exposure to Protefix ${ }^{\circledR}$ gel in concentrations of $1 \%, 5 \%$, and $25 \%$, a significant increase of the reaction intensity was observed, especially after $24 \mathrm{~h}$.

\section{Discussion}

Currently, in prosthetic practice it is extremely important to carefully select preparations for adhesive dentures so as not to provoke any injuries or allergic reaction. In the present study, Protefix ${ }^{\circledR}$ gel was verified in an in vitro approach on human fibroblasts derived from primary gingival tissue. This therapeutic gel is designed in particular for those patients who have problems with mucosa, recurrent aphthous stomatitis (RAS) and other mucosa gingival problems. Moreover, triester glycerol oxide is the topical agent which has the property of adherence to the oral mucosa by forming a lipid film which protects against mechanical trauma and may help to reduce oral tissue moisture loss and inflammation [13-15]. Many clinical randomized investigations have been conducted to assess the efficiency of Protefix ${ }^{\circledR}$ gel for patients suffering for various problems with gingival mucosa such as recurrent aphthous stomatitis (RAS) [16]. However, there have not been any investigations in which the safety for surrounding gingival tissue has been confirmed in vitro. Our in vitro study showed that Protefix ${ }^{\circledR}$ gel activated proliferation of human gingival fibroblasts. Cell viability slightly decreased only after incubations of HGF with 100 and $75 \%$ gel concentrations. The lower concentrations of evaluated gel were involved in significant stimulating properties of HGF cells. The observed increase even exceeded $50 \%$ in relation to untreated control cells. This was also confirmed by another experiment in which cell migration ability was tested. Our prolonged observations of up to 48 hours demonstrated the positive effect of Protefix ${ }^{\circledast}$ gel on human gingival fibroblasts growth. The expression of collagen III was also examined semi-quantitatively by the immunocytochemical method. The expression of collagen III in control, untreated cells revealed only pattern expression. However, after exposure to Protefix ${ }^{\circledast}$ gel in concentrations of 1,5 or $25 \%$ human gingival fibroblasts demonstrated significant increases in the color reaction, especially after 24 hours. The results showed that Protefix ${ }^{\circledast}$ gel was involved in regeneration, due to increased collagen III expression in treated cells. This type of collagen is mainly present in the tissue formed from fibroblasts before type I collagen is produced. Its significant expression is observed during wound healing, where it forms fibers of connective tissue and proper connective tissue. Collagen III is produced by fibroblasts and is primarily involved in the formation of the peptide scaffolds of collagen I. This process could play the main role inter alia in wound healing promotion and especially in periodontal ligament tissue regeneration [17].

In conclusion, the results of our study suggest that the proper selection of the regeneration materials for gingival tissue used in everyday prosthetic practice is essential. Our results prove that the tested gel has regenerative properties, which can be of great importance in the treatment of gingivitis after retraction, surgical procedures, or even with ordinary daily injuries.

\section{Acknowledgments}

This research was partially performed in the Screening Laboratory of Biological Activity Testing and Collection of Biological Material, Faculty of Pharmacy and the Division of Laboratory Diagnostics, Wrockaw Medical University, supported by the ERDF Project within the Innovation Economy Operational Program POIG.02.01.00-14-122/09.

\section{References}

1. Yu GY. Oral and maxillofacial surgery: Current and future. Ann Maxillofac Surg. 2013; 3(2): 111-112, doi: 10.4103/22310746.119209, indexed in Pubmed: 24205468.

2. Wolf DL, Lamster IB. Contemporary concepts in the diagnosis of periodontal disease. Dent Clin North Am. 2011; 55(1): 47-61, doi: 10.1016/j.cden.2010.08.009, indexed in Pubmed: 21094718.

3. Góra J, Lis A, Kula J, et al. Chemical composition variability of essential oils in the ontogenesis of some plants. Flavour Fragrance J. 2002; 17(6): 445-451, doi: 10.1002/ffj.1126. 
4. Sterczała B, Kulbacka J, Saczko J, et al. : Evaluation of keratinized gingival fibroblast proliferation after Protefix ${ }^{\circledR}$ gel application, in the aspect of wound healing in elderly patients, J Stoma 2019; 72. ; 1: 8-11.

5. Upadhay RK. : Plant natural products: Their pharmaceutical potential against disease and drug resistant microbial pathogens, J Pharm Res. 2011; 4(4): 1179-1185.

6. Sakagami H, Tomomura M. Dental Application of Natural Products. Medicines (Basel). 2018; 5(1), doi: 10.3390/medicines5010021, indexed in Pubmed: 29443874.

7. Cimanga K, Kambu K, Tona L, et al. Correlation between chemical composition and antibacterial activity of essential oils of some aromatic medicinal plants growing in the Democratic Republic of Congo. J Ethnopharmacol. 2002; 79(2): 213-220, doi: 10.1016/s0378-8741(01)00384-1, indexed in Pubmed: 11801384.

8. Park MJ, Gwak KS, Yang I, et al. Effect of citral, eugenol, nerolidol and alpha-terpineol on the ultrastructural changes of Trichophyton mentagrophytes. Fitoterapia. 2009; 80(5): 290-296, doi: 10.1016/j.fitote.2009.03.007, indexed in $\mathrm{Pu}-$ bmed: 19345255.

9. Omidbeygi M, Barzegar M, Hamidi Z, et al. Antifungal activity of thyme, summer savory and clove essential oils against Aspergillus flavus in liquid medium and tomato paste. Food Control. 2007; 18(12): 1518-1523, doi: 10.1016/j.foodcont.2006.12.003.

10. Dominiak M, Łysiak-Drwal K, Saczko J, et al. A simple and established method of tissue culture of human gingival fibroblasts for gingival augmentation. Folia Histochem Cytobiol.
2008; 46(1): 117-119, doi: 10.2478/v10042-008-0017-4, indexed in Pubmed: 18296274.

11. Volk SW, Wang Y, Mauldin EA, et al. Diminished type III collagen promotes myofibroblast differentiation and increases scar deposition in cutaneous wound healing. Cells Tissues Organs. 2011; 194(1): 25-37, doi: 10.1159/000322399, indexed in Pubmed: 21252470.

12. Drąg-Zalesińska M, Rembiałkowska N, Borska S, et al. A New Betulin Derivative Stimulates the Synthesis of Collagen in Human Fibroblasts Stronger than its Precursor. In Vivo. 2019; 33(4): 1087-1093, doi: 10.21873/invivo.11577, indexed in Pubmed: 31280196.

13. Jurge S, Kuffer R, Scully C, et al. Mucosal disease series. Number VI. Recurrent aphthous stomatitis. Oral Dis. 2006; 12(1): 1-21, doi: 10.1111/j.1601-0825.2005.01143.x, indexed in Pubmed: 16390463.

14. Scully C, Porter S. Oral mucosal disease: Recurrent aphthous stomatitis. Br J Oral Maxillofac Surg. 2008; 46(3): 198-206, doi: 10.1016/j.bjoms.2007.07.201.

15. Baccaglini L, Lalla RV, Bruce AJ, et al. Urban legends: recurrent aphthous stomatitis. Oral Dis. 2011; 17(8): 755-770, doi: 10.1111/j.1601-0825.2011.01840.x, indexed in Pubmed: 21812866.

16. Ofluoglu D, Ergun S, Warmakulasuiriya S, et al.: Triester Glycerol Oxide gel in the treatment of minor RAS. Med Oral Patol Oral Cir Bucal. 2017; 22(2): 159-66.

17. Kumada Y, Zhang S. Significant type I and type III collagen production from human periodontal ligament fibroblasts in 3D peptide scaffolds without extra growth factors. PLoS One. 2010; 5(4): e10305, doi: 10.1371/journal.pone.0010305, indexed in Pubmed: 20421985.

Submitted: 6 March, 2019

Accepted after reviews: 9 June, 2020 Available as AoP: 22 June, 2020 
